\title{
Large Gastric Lipoma
}

\author{
Sharma BK, ${ }^{1}$ Dhakal OP
}

\author{
${ }^{1}$ Department Of Radiodiagnosis \\ ${ }^{2}$ Department Of Medicine
}

Sikkim Manipal Institute of Medical Sciences (SMIMS) and Central Referral Hospital (CRH)

Sikkim, India

\section{Corresponding Author \\ Barun Kumar Sharma \\ Department Of Radiodiagnosis}

Sikkim Manipal Institute of Medical Sciences (SMIMS) and Central Referral Hospital (CRH)

5th Mile, Tadong, Gangtok

Sikkim, India

Email: drbarun2003@yahoo.com

Citation

Sharma BK, Dhakal OP. Large Gastric Lipoma. Kathmandu Univ Med J 2012;39(3):70-72.

\begin{abstract}
Gastric lipoma is a rare benign tumor and seen in five percent of gastro-intestinal lipomas and accounts for less than one percent of all gastric tumors. Gastric lipomas are located submucosally and usually in antral region of Stomach. Computed tomography is considered as valuable tool in the diagnosis of gastrointestinal lipomas. Due to their relative rarity, gastric lipomas are often left out of the differential diagnosis for upper gastro-intestinal submucosal masses. We report a case of 70 year female that presented with upper abdominal pain since last two years. Abdominal Computed tomography revealed a large gastric lipoma in antral region. Patient refused for any surgical intervention due to old age. Patient was provided symptomatic treatment and was under regular followup.
\end{abstract}

\section{KEY WORDS}

Benign gastric tumor, large gastric lipoma, upper abdominal pain

\section{INTRODUCTION}

Gastric lipoma is a rare benign tumor and seen in five percent of gastro-intestinal lipomas and accounts for less than one percent of all gastric tumors. ${ }^{1}$ There are approximately 200 cases of gastric lipoma reported in world literature, the first dated 1842 and attributed to Professor Jean Cruveilhier pathology at the University of Paris. ${ }^{2}$ Gastro-intestinal lipomas are mostly seen in colon, ileum and jejunum. ${ }^{3}$ Gastric lipomas are located submucosally and usually in antral region of Stomach. Small gastric lipomas are mostly asymptomatic. Large gastric lipoma (>3$4 \mathrm{~cm}$ ) commonly presents with gastric bleeding secondary to tumor ulceration. It is seen as submucosal mass in upper gastro-intestinal endoscopy, sometimes along with ulceration producing bull's eye appearance. It is difficult to differentiate gastric lipoma from other gastric stromal tumor by endoscopy. Computed Tomography (CT) is considered as valuable tool in the diagnosis of gastrointestinal lipomas. 4-7 The lesions appear as well circumscribed, uniform, fatty density mass with an attenuation value ranging from -70 to $-120 \mathrm{HU}$. Therefore, Gastric lipoma is definitively diagnosed using $\mathrm{CT}$, which obviates the need of endoscopy or even biopsy if the patient is asymptomatic. ${ }^{6,7}$

\section{CASE REPORT}

A 70 year old female presented in medicine outpatient department of Central Referral Hospital, Sikkim, India with complaint of upper abdominal pain for last two years. After taking consent, physical examination was done which resulted unremarkable. Complete blood count was within normal limit. On endoscopy, a large submucosal mass with depression in the center noted in the antral region. On abdominal Ultrasonography, an echogenic mass noted in epigastric region along with associated cholelithiasis (fig 1). On Contrast enhanced computed tomography (CECT) abdomen, a large well defined fat density mass measuring 


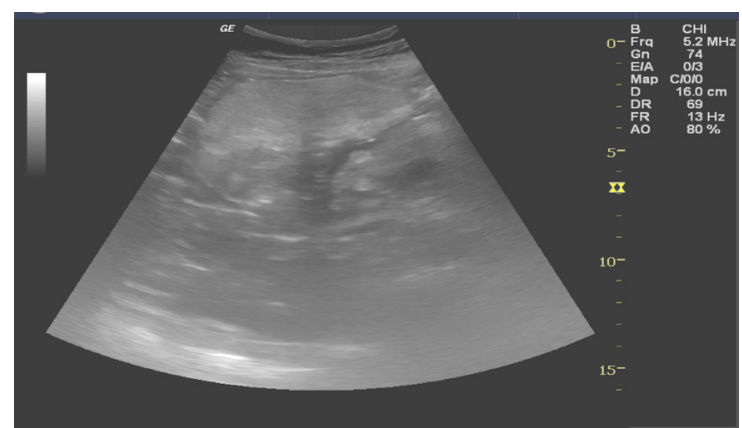

Figure 1. Ultrasonography showing large echogenic mass in epigastric region.

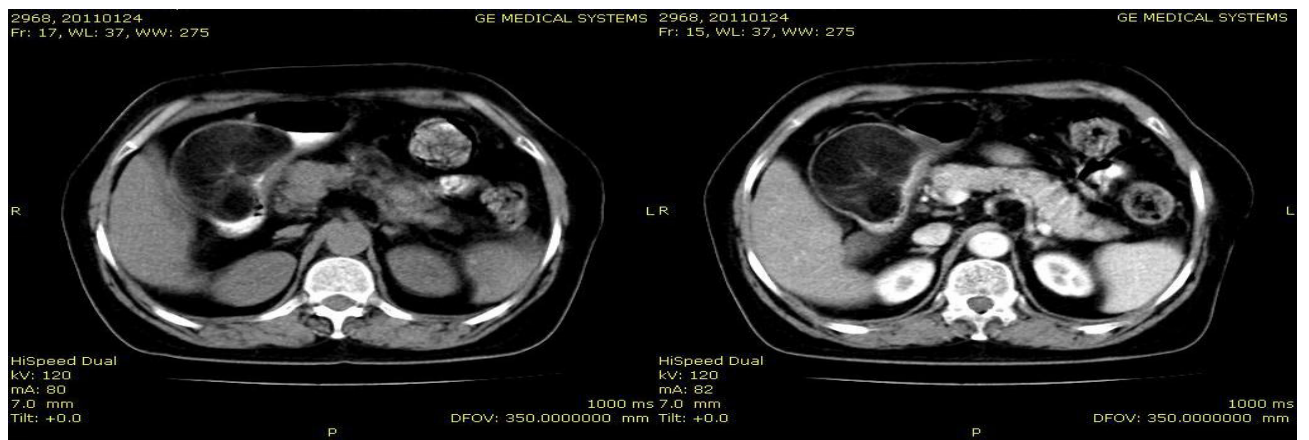

Figure $2 \mathrm{~A}$ and $2 \mathrm{~B}$. NECT and CECT abdomen showing a large well defined fat density mass in lesser curvature wall of pyloric antrum of stomach causing luminal narrowing without any evidence of gastric obstruction along with small depression in the luminal aspects of the mass and showing few soft tissue strandings within the mass.

$7.5 \mathrm{~cm} \times 5.5 \mathrm{~cm}$ noted in lesser curvature wall of antrum of stomach suggesting gastric lipoma causing luminal narrowing without any evidence of gastric obstruction along with small depression in the luminal aspects of the mass and showing few soft tissue strandings within the mass (Fig 2A and Fig 2B). Patient was advised for surgery but refused due to her old age and fragile health. Patient was provided symptomatic treatment and was under regular follow-up.

\section{DISCUSSION}

Gastro-intestinal lipoma is a benign tumor of mature adipose tissue surrounded by a fibrous capsule. ${ }^{8}$ Gastric lipoma is a rare benign tumor and seen in five percent of gastro-intestinal lipomas and accounts for less than one percent of all gastric tumors. ${ }^{1}$ Gastro-intestinal lipomas are mostly seen in colon, ileum and jejunum. ${ }^{3}$ Gastric lipomas mostly originate from the submucosal layer, though it may arise from either subserosal or intramural layer. The antrum is the commonest site for gastric lipoma. Small gastric lipomas are mostly asymptomatic. Kim DD et al reported a case of gastric lipoma with no clinical complaint and found in a routine endoscopy. ${ }^{9}$ Large gastric lipoma $(>3-4 \mathrm{~cm})$ can present as upper gastrointestinal bleeding and as gastric outlet obstruction.

CT and endoscopy complement each other in diagnosing gastric lipoma. In endoscopy, gastric lipomas are usually seen as submucosal mass and sometimes with superficial ulceration producing bull's eye appearance. During endoscopy, gastric lipoma may reveal tenting sign; the naked fat sign, and the cushion sign. ${ }^{10,11}$ High resolution ultrasound can be used to visualize submucosal gastric masses. ${ }^{12} \mathrm{CT}$ is considered as valuable tool in the diagnosis of gastrointestinal lipomas. ${ }^{4-7}$ The lesion appears as well circumscribed, uniform, fatty density mass with an attenuation value ranging from -70 to $-120 \mathrm{HU}$. Surgical resection is required in symptomatic large tumors presenting with upper gastrointestinal bleeding and as gastric outlet obstruction. Relapse of gastric lipoma is rare after resection as it is always a benign tumor. ${ }^{13}$ Although gastric lipomas are rare; they should be included in the differential diagnosis when evaluating submucosal gastric masses.

\section{REFERENCES}

1. Fernandez MJ, Davis RP, Nora PF. Gastrointestinal lipomas. Arch Surg 1983;118:1081-1083.

2. Treska V, Pesek M, Kreuzberg B, Z Chudacek, Ludvikova M, Topolcan O. Gastric lipoma presenting the upper gastrointestinal obstruction. J Gastroenterol 1998,33:716-719.

3. Taylor AJ, Stewart ET, Dodds WJ. Gastrointestinal lipomas: a radiologic and pathologic review. AJR Am J Roentgenol 1990;155:1205-1210.

4. Heiken JP, Forde KA, Golde RP. Computerized tomography as a definitive method of diagnosing gastrointestinal lipomas. Radiology 1982;142:743-745.

5. Megibow A, Redmond P, Bosniak M. Diagnosis of gastrointestinal obstruction. J Gastroenterol 1998;33:716-719.

6. Imoto $T$, Nobe $T$, Koga M, Miyamoto $Y$, Nakata H. Computed tomography of gastric lipomas. Gastrointest Radiol 1983;8:129-131.

7. Kang JY, Chan-Wilde C, Wee A. Role of computed tomography and endoscopy in the management of alimentary tract lipoma. Gut 1990; 31:550-553. 
8. Thomson WM, Kende Al, Levy AD. Imaging characteristics of gastric lipomas in 16 adult and pediatric patients. Am J Roentgenol 2003; 181:981-985.

9. Kim DD, Tsai Al, Otani AR, Puglia CR, Malheiros CA. Gastric lipoma case report. Rev Col Bras Cir 2011;38:205-206.

10. DeBeer RA, Shinye H. Colonic lipomas. Gastroenterol Endosc 1975; 22:90-91.
11. Taylor AJ, Stewart ET, Dodds WJ. Gastrointestinal lipomas: A radiologic and pathologic view. AJR Am J Roentgenol 1990;55:1205-1210.

12. Tsai TL, Changchien CS, Hu TH, Hsiaw CM. Demonstration of gastric submucosal lesions by high resolution transabdominal sonography. $J$ Clin Ultrasound 2000;28:125-131.

13. Dargan $P$, Sodhi $P$, Jain BK. Bleeding gastric lipoma: Case report and review of literature. Trop Gastroenterol 2003;24:213-214. 